\title{
Increasing prevalence of Type II diabetes in American Indian children
}

\author{
D. Dabelea, R. L. Hanson, P. H. Bennett, J. Roumain, W. C. Knowler, D. J. Pettitt
}

National Institute of Diabetes and Digestive and Kidney Diseases, National Institutes of Health, Phoenix, Arizona, USA

\begin{abstract}
Summary Until recently, Type II diabetes was considered rare in children. The disease is, however, increasing among children in populations with high rates of Type II diabetes in adults. The prevalence of Type II diabetes was determined in 5274 Pima Indian children between 1967 and 1996 in three 10-year time periods, for age groups 5-9, 10-14 and 15-19 years. Diabetes was diagnosed using World Health Organisation criteria, based on an oral glucose tolerance test. The prevalence of diabetes increased over time in children aged 10 years and over: in boys from $0 \%$ in $1967-1976$ to $1.4 \%$ in $1987-1996$ in the $10-14$ year old age group, and from $2.43 \%$ to $3.78 \%$ for age group $15-19$ and in girls from $0.72 \%$ in $1967-1976$ to $2.88 \%$ in $1987-1996$ in the $10-14$ year old age group, and from $2.73 \%$ to $5.31 \%$ for age group $15-19$ years. Along with the increase in the prevalence of Type II
\end{abstract}

diabetes $(p<0.0001)$, there was an increase in weight (calculated as percentage of relative weight, $p<0.0001$ ), and in frequency of exposure to diabetes in utero $(p<0.0001)$. The increasing weight and increasing frequency of exposure to diabetes in utero accounted for most of the increase in diabetes prevalence in Pima Indian children over the past 30 years. Type II diabetes is now a common disease in American Indian children aged 10 or more years and has increased dramatically over time, along with increasing weight. A vicious cycle related to an increase in the frequency of exposure to diabetes in utero appears to be an important feature of this epidemic. [Diabetologia (1998) 41: 904-910]

Keywords Prevalence, epidemic, children, Type II diabetes, obesity, diabetic pregnancy.
The Pima Indians, who live in central Arizona, have the world's highest recorded prevalence and incidence of diabetes mellitus [1,2,3]. About $50 \%$ of Pima adults over 35 years of age suffer from this condition [4]. Diabetes in the Pimas, even when it develops at young ages, is Type II diabetes, as the disease is not associated with islet cell antibodies, ketoacidosis or insulin dependence [5, 6, 7]. Both genetic and environmental factors contribute

Received: 30 January 1998 and in revised form: 18 April 1998

Corresponding author: Dr D. Dabelea, Diabetes and Arthritis Epidemiology Section, National Institute of Diabetes and Digestive and Kidney Diseases, National Institutes of Health, 1550 East Indian School Road, Phoenix, AZ 85014, USA Abbreviations: MODY, Maturity onset diabetes of the young; OR, odds ratio; CI, confidence interval. to the high rate of diabetes seen in the Pima Indians. The risk indicators include certain genetic markers, obesity, diet, parental diabetes, prenatal hyperglycaemic environment and both low and high birthweight [8]. The prevalence of Type II diabetes in the Pima Indians has been increasing during this century and has been higher in recent years than it was thirty years ago. Moreover, the disorder now seems to be quite common even among Pima children $[2,4,9]$.

Few studies of Type II diabetes in children have been published and the disease is generally considered rare in children and adolescents $[10,11]$. In children Type II diabetes seems to be increased in populations with high rates of diabetes among adults, such as the Pima Indians [11, 12,13,14]. To document changes, the prevalence of Type II diabetes in Pima children was determined in 5274 persons aged 5 to 
19 years, residing in the Gila River Indian Community in central Arizona, during a 30 year period.

\section{Subjects and methods}

The residents of the Gila River Indian Community have been invited to participate in research examinations approximately every 2 years, regardless of health status and since 1967 children aged 5 years and over have been examined [1]. Standardized biennial examinations include measurements of venous plasma glucose $2 \mathrm{~h}$ after a $75 \mathrm{~g}$ oral glucose load, height, weight and blood pressure. Medical history is recorded, medical records reviewed, and data on family relationship collected.

This analysis includes Pima subjects aged 5 to 19 years whose heritage was at least half Pima or Tohono O'odham or a mixture of these two closely related tribes and who resided in the community at any time between 1 January 1967 and 31 December 1996. Table 1 shows the number of children examined in each five-year age group and 10-year time period. One or more $75 \mathrm{~g}$ oral glucose tolerance tests were given to 5274 children. Diabetes and impaired glucose tolerance were diagnosed by World Health Organisation (WHO) criteria [15]. Blood pressure was measured with the subject supine and Korotkoff sounds I and IV were used for systolic and diastolic pressures, respectively. Birthweights were obtained from the medical records of 2992 of the participants. To estimate obesity, the ratio of each child's weight to a predicted weight was taken and was expressed as a percentage to obtain relative weight. Predicted weight was calculated with linear regression analysis in each age group and sex, as a function of age and height. Exposure to diabetes in utero was considered present if the mother had diabetes diagnosed prior to delivery of the child and absent if diabetes was diagnosed after delivery or if the mother had a non-diabetic oral glucose tolerance test following delivery. Women without a diagnosis of diabetes who were not tested following the child's delivery were considered unknown (mothers of 639 children), and their children were not included in analyses of diabetes in utero.

The age and sex specific prevalence rates of diabetes, as well as the distribution of percentage relative weight, were assessed in three 10-year time periods (1 January 1967 to 31 December 1976, 1 January 1977 to 31 December 1986, and 1 January 1987 to 31 December 1996) for the age groups: 5-9, 10-14 and 15-19 years, using data from the last examination of each subject in each age group in each time period. The risk of diabetes in the children attributable to exposure to diabetes in utero was determined for each time period, using data from the last examination in each time period. The effects of percentage relative weight, exposure to diabetes in utero, and birthweight on prevalence of Type II diabetes were also examined for each age group, using data from the last examination in each age group.

For all other statistical analyses, all available data were used for each subject. The analyses were conducted with the Statistical Package for Interactive Data Analysis (SPIDA, Statistical Computing Laboratory, Eastwood, Australia), using the generalized estimating equations of Zeger and Liang [16], which allow for lack of independence among repeated observations on the same person. Once a person had diabetes, diabetes was considered to be present at all subsequent examinations. The significance of differences in prevalence of diabetes and exposure to diabetes in utero over time were assessed by logistic regression analyses using binomial generalized estimating equations. Multiple logistic regression analyses with diabetes as the dependent variable were also performed with the
Table 1. Children examined, in each age group and time period of the study

\begin{tabular}{lcllrl}
\hline $\begin{array}{l}\text { Years of } \\
\text { examination }\end{array}$ & $\begin{array}{l}\text { Age } \\
\text { group } \\
\text { (years) }\end{array}$ & \multicolumn{2}{l}{ Examined } & $\begin{array}{l}\text { Ascer- } \\
\text { tainment }\end{array}$ \\
\cline { 3 - 5 } & Boys & Girls & Total & \\
\hline $1967-76$ & $5-9$ & 602 & 596 & 1198 & 77.2 \\
& $10-14$ & 628 & 909 & 1337 & 89.8 \\
& $15-19$ & 442 & 590 & 1032 & 75.9 \\
$1977-86$ & $5-9$ & 339 & 371 & 710 & 53.2 \\
& $10-14$ & 692 & 672 & 1364 & 96.3 \\
& $15-19$ & 495 & 608 & 1103 & 72.9 \\
$1987-96$ & $5-9$ & 514 & 518 & 1032 & 60.9 \\
& $10-14$ & 548 & 555 & 1103 & 72.9 \\
& $15-19$ & 428 & 535 & 963 & 69.4 \\
\hline
\end{tabular}

a Number of children examined divided by the number residing in the community for at least two years in each age group and time period

Table 2. Clinical characteristics of children at first examination with diabetes

\begin{tabular}{lccc}
\hline & \multicolumn{3}{c}{ Age groups (years) } \\
\cline { 2 - 4 } & $5-9$ & $10-14$ & $15-19$ \\
\hline Number & 3 & 44 & 78 \\
Mean age at diagnosis (years) & 8.4 & 12.4 & 16.9 \\
Mean age at first exam (years) & 8.4 & 12.8 & 17.5 \\
Height (cm) & 137 & 158 & 166 \\
Weight (kg) & 41.7 & 80.6 & 96.5 \\
2-h glucose (mmol/l) & 16.4 & 15.6 & 14.8 \\
Mean SBP (mm Hg) & 103 & 115 & 126 \\
Mean DBP (mm Hg) & 36 & 63 & 70 \\
Mean cholesterol (mmol/l) & 3.8 & 3.7 & 4.3 \\
\% exposed to diabetes in utero & 33.3 & 48.8 & 18.3 \\
\% with birthweight ${ }^{\mathrm{a}}$ & & & \\
$\quad<2.5 \mathrm{~kg}$ & 0 & 12.0 & 6.1 \\
2.5-4.5 kg & 66.7 & 80.0 & 83.7 \\
$\geq 4.5 \mathrm{~kg}$ & 33.3 & 8.0 & 10.2 \\
\hline
\end{tabular}

geometric means for height, weight, 2-h glucose

SBP, DBP = systolic and diastolic blood pressure

a birthweight was missing for 19 children in 10-14 and 29 children in 15-19-year-old age groups

same technique to control for confounders. Similarly, linear generalized estimating equation models were used to perform linear regression analyses with the logarithm of weight as the dependent variable. Statistical validity of the models was assessed by examination of the residual values. Since the interaction term between age and sex was significant in most of the models, it was included as an independent variable in each analysis.

\section{Results}

Clinical characteristics of the 125 children with diabetes, at the first research examination at or after the time of diagnosis, are shown in Table 2. The youngest age at diagnosis was 3.5 years. In 98 subjects diabetes 


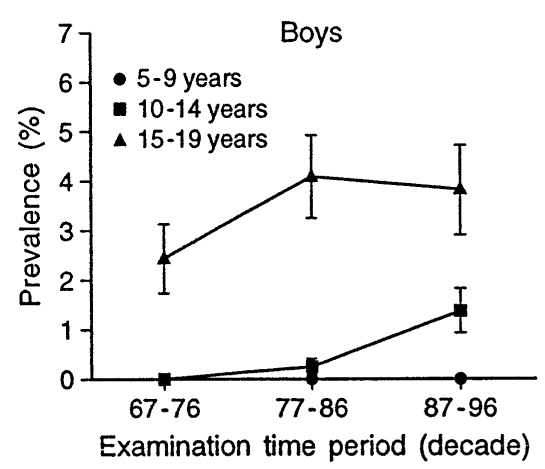

Fig. 1. Sex-specific prevalence of diabetes (standard error bars) in Pima children, by age group, in three time periods from 1967 to $1996, p<0.0001$ for temporal trend (binomial generalized estimating equations controlled for age, sex and agesex interaction, allowing use of data from all exams for each subject). Age groups shown in years

Table 3. Diabetes prevalence (\%) by relative weight, exposure to diabetes in utero and birth weight, in three age groups

\begin{tabular}{lllcc}
\hline Age group (years) & & \multicolumn{2}{l}{$(\%)$} \\
\cline { 3 - 5 } & & $5-9$ & $10-14$ & $15-19$ \\
\hline Group of relative weight & $<90$ & 0.00 & 0.13 & 0.89 \\
$(\%)$ & $90-110$ & 0.11 & 0.76 & 2.51 \\
& $\geq 110$ & 0.32 & 3.22 & 7.61 \\
Exposure to diabetes & No & 0.06 & 0.62 & 2.75 \\
in utero & Yes & 0.87 & 15.56 & 24.72 \\
Birthweight group $(\mathrm{kg})$ & $<2.5$ & 0.00 & 2.83 & 6.89 \\
& $2.5-3.5$ & 0.10 & 0.51 & 2.98 \\
& $3.5-4.5$ & 0.15 & 1.46 & 2.77 \\
& $\geq 4.5$ & 1.92 & 3.66 & 13.4 \\
\hline
\end{tabular}

Based on last examination in each age group.

$p<0.001$, controlled for age and sex, for each variable; Ushaped relation with birthweight group

was diagnosed at a research examination, and in 27 children diagnosis was based on a previous history of diabetes. Of 125 children with diabetes, 22 were treated with insulin at the last examination (three because of pregnancy, two because of concomitant illness), and the median time period between diagnosis and start of insulin therapy was 7.5 years. Of the 60 children with youngest age at diagnosis (below 15 years), only five were treated with insulin at the last examination.

Figure 1 shows the sex-specific prevalence rates of diabetes in three 10-year time periods by age group. Data from the last examination in each age group and time period were adjusted for age in 1-year intervals by the direct method [2], using the uniform age distribution within each age group as the reference population. In each sex, the prevalence was higher in older ages ( $p<0.003$ for boys, $p<0.0001$ for girls). Except for the youngest age group, in which only a few cases were recorded (two in 1967-1976 and one

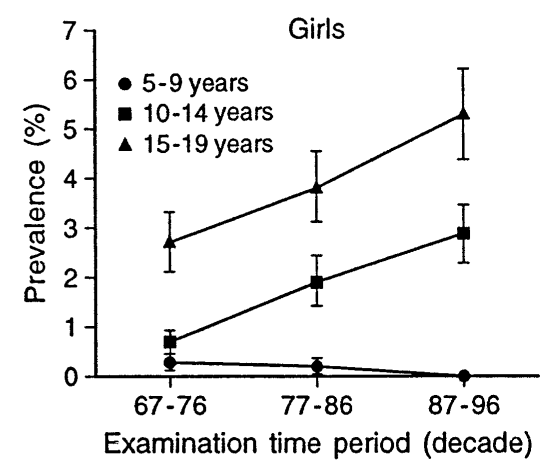

in 1977-1986), the prevalence of diabetes increased over time $(p<0.0001$, controlled for age and sex).

Obesity, exposure to diabetes in utero, low birth weight and high birth weight have each been shown previously to be important risk factors for diabetes in Pima adults $[8,17,18]$, and they are also in Pima children (Table 3). Prevalence of diabetes increased significantly with increasing relative weight, and with exposure to diabetes in utero. The prevalence of diabetes showed a U-shaped relation with birth weight, with the higher rates in those in the highest ( $\geq 4.5 \mathrm{~kg}$ ) and lowest $(<2.5 \mathrm{~kg}$ ) birth weight groups.

The mean weight of Pima boys and girls increased over time $(p<0.0001$, controlled for age and height, for each sex). Moreover, except for the 5-9 year old boys, the percentage relative weight value in each centile of the distribution is higher in later time periods than in earlier ones, especially in the higher centiles (Fig. 2). The percent of children who had been exposed to diabetes in utero (Table 4$)$ also increased considerably over the 30 year period $(p<0.0001)$, and this is associated with a doubling of the amount of diabetes in the children that may be attributed to intrauterine exposure to diabetes. The distribution of birth weights, however, did not change over time $(p=0.099)$.

To determine possible explanations for the increase in diabetes prevalence over time, multiple logistic regression analyses were performed, restricted to 2738 children for whom all variables were recorded (Table 5). When controlled for age and sex (model 1), birth date was significantly associated with diabetes (adjusted odds ratio per 10 years $=1.46,95 \%$ confidence interval $=1.07-1.98)$. We added to this model each of the variables: birth weight category (low birth weight vs normal and high birth weight vs normal, model 2), weight and height (model 3 ), and intrauterine exposure to diabetes (model 4). The effect of birth date as a predictor of diabetes was unchanged when birth weight categories were added: (model 2, odds ratio [OR] per 10 years $=1.45)$. However, birth date no longer significantly predicted diabetes when either weight and height (model 3, OR per 10 years $=1.34$ ), or exposure to diabetes in utero (model 4, OR per 10 years $=1.29$ ), were included. When controlled for age, sex, birth weight categories, 

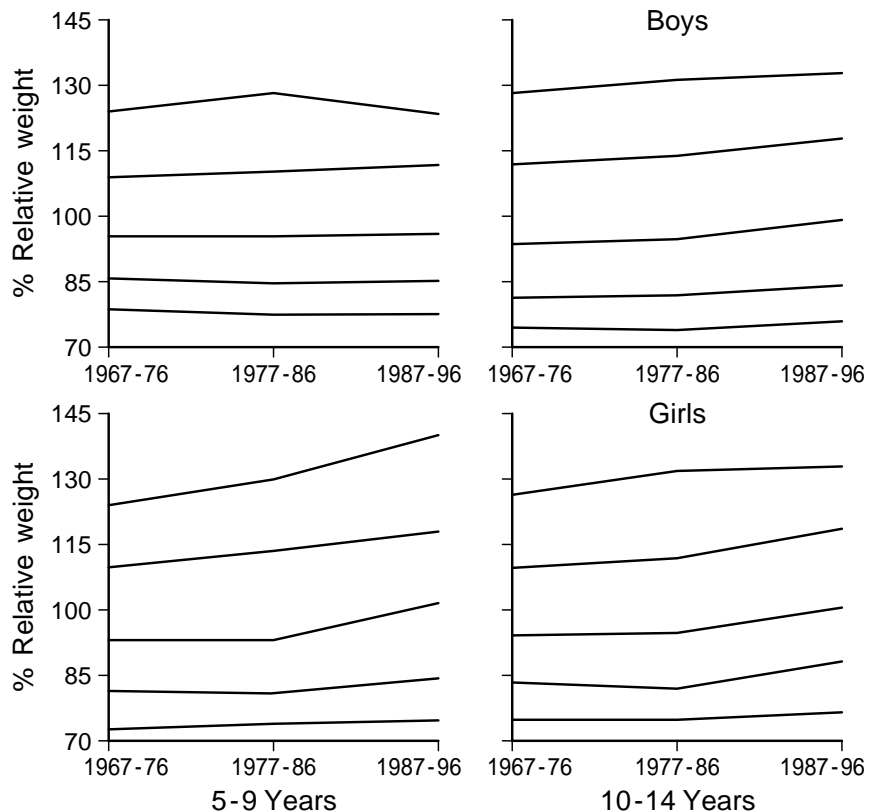

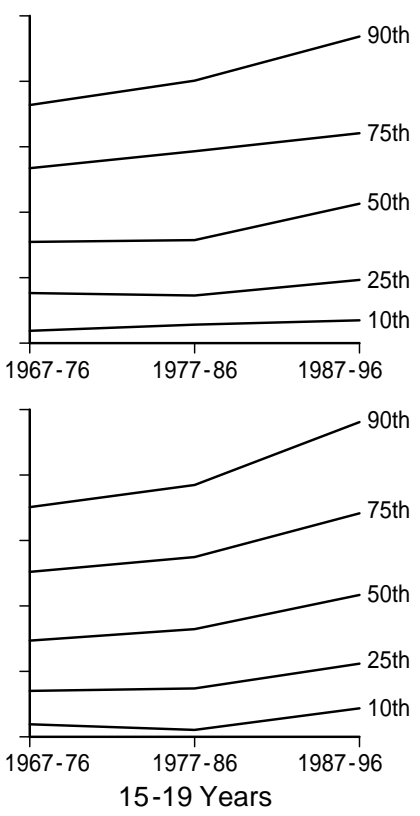

Fig. 2. Distribution of percent relative weight in Pima Indian children, by age group and sex, in three time periods. Note that the 50th centiles are less than 100 because the relative weight distribution is positively skewed. Centiles: 10th 25 th 50th 75th 90th

Table 4. Frequency of exposure to diabetes in utero and attributable risk for diabetes, in three time periods

\begin{tabular}{lccc}
\hline Years of Examination & $67-76$ & $77-86$ & $87-96$ \\
\hline Exposure to diabetes in utero (\%) & 2.05 & 4.01 & 7.51 \\
Odds Ratio for diabetes & 13.5 & 10.3 & 10.4 \\
Attributable risk $(\%)^{\mathrm{a}}$ & 18.1 & 23.7 & 35.4 \\
\hline
\end{tabular}

${ }^{\mathrm{a}}=(\mathrm{OR}-1) \mathrm{P} / \mathrm{OR} ; \mathrm{OR}=$ odds ratio, $\mathrm{P}=$ proportion of cases that is exposed

Table 5. The effects of birth date (per 10 years), adjusted for birthweight, exposure to diabetes in utero, and weight and height, by logistic regression analysis in 2738 Pima children

\begin{tabular}{llll}
\hline Model & Covariates & OR & $95 \%$ CI \\
\hline 1. & age, sex & 1.46 & $1.07-1.98$ \\
2. & age, sex, birthweight categories & 1.45 & $1.06-1.98$ \\
3. & age, sex, height, weight & 1.34 & $0.95-1.87$ \\
$4 . \quad$ & age, sex, exposure to diabetes in utero & 1.29 & $0.92-1.84$ \\
$5 . \quad$ & 1.14 & $0.60-1.71$ \\
& age, sex, birthweight categories \\
& height, weight, exposure to diabetes & & \\
& in utero & & \\
\end{tabular}

a low $(<2.5 \mathrm{~kg})$ vs normal $(2.6-4.4 \mathrm{~kg})$, high $(\geq 4.5 \mathrm{~kg})$ vs normal $(2.5-4.4 \mathrm{~kg})$

intrauterine exposure to diabetes, weight and height, the odds ratio of birth date was substantially lower [model 5, OR per 10 years $=1.15,95 \%$ confidence interval $(\mathrm{CI})=0.60-1.71]$; thus most of the increase in diabetes prevalence over time was accounted for by the effect of weight and height, and exposure to diabetes in utero. The strongest single risk factor for Type II diabetes in Pima children was exposure to diabetes in utero $(\mathrm{OR}=10.41,95 \% \mathrm{CI}=4.31-25.12$, $p<0.0001$ ), and in offspring of diabetic pregnancies, no variable, other than age, was significantly associated with diabetes (data not shown). In offspring of non-diabetic pregnancies only, birth date no longer significantly predicted diabetes, when controlled for age, sex, weight and height (OR per 10 years $=1.19$, $95 \% \mathrm{CI}=0.68-2.24)$.

\section{Discussion}

Diabetes mellitus in children of European or African American origin is usually considered to be Type I diabetes. Although it has been recognized that some children with diabetes do not require insulin for survival and rarely develop ketoacidosis [19], until recently, Type II diabetes mellitus has not been considered a common disease in children [20].

Differentiating Type II diabetes from Type I diabetes in children can be a diagnostic challenge [20]. Even when it occurs at a young age, diabetes in Pimas is not associated with high titres of islet cell antibodies [5], insulin and C-peptide concentrations are not subnormal [8], and exogenous insulin is not required to prevent ketosis $[6,7]$. For our patients, the clinical features suggest Type II rather than Type I diabetes and include family history of Type II diabetes, lack of symptoms at diagnosis, presence of obesity and low frequency of insulin treatment. It thus appears that diabetes in Pima children is primarily, perhaps entirely, Type II diabetes.

Maturity onset diabetes of the young (MODY) is also a common cause of diabetes recognized in Cau- 
casian children [21]. Although in Pima children the transmission of diabetes from parents to offspring is consistent with an autosomal mode of inheritance [22-24], there is no evidence for linkage to known MODY loci [25], and no individuals with MODY-associated glucokinase [26], HNF1 $\alpha$ or HNF4 $\alpha$ mutations (D.B.Thompson, L.Baier, unpublished data) have been found. Therefore, diabetes due to variation in the known MODY genes does not appear to account for diabetes among Pima children.

Type II diabetes is reported to account for 2 to $3 \%$ of all patients with diabetes mellitus aged 0 to 19 years in the United States [27, 28], but the prevalence is higher among children in populations with a relatively high prevalence of Type II diabetes in adults [12]. In early data from Pima Indians [6], only six subjects, all aged 15-24 years at the time (1 January 1966) had a diagnosis of diabetes, giving a point prevalence of 9.1/1000 in this age group and a rate of 2.7/1000 for all ages (0-24 years), compared with 1.89 (mainly Type I diabetes) per 1000 Caucasian school-age children in Minnesota [29].

As Pima children have been systematically tested for diabetes for 30 years, we have estimated the prevalence of diabetes, by age groups, in various time periods. The rates in the last 10 years are the highest reported to date. Persons seen in the later periods might have a greater prevalence of diabetes by virtue of having been tested more often, even if the diagnosis was not confirmed at a subsequent examination. To assess this potential bias in the temporal increase in diabetes prevalence, the analyses were repeated by counting as cases only those persons who met glucose tolerance test criteria for diabetes or were treated with insulin or oral agents at the time of examination, without consideration of previous diagnoses. The results were similar to those shown. The rates are much higher than is the prevalence of Type I diabetes in children in the United States - approximately $0.04 \%$ at age 5 years to about $0.33 \%$ by age 18 years [30].

Type II diabetes has also been documented in First Nations (American Indian) children in Manitoba, with a prevalence of 0.53 per 1000 children 7 to 14 years of age $[31,32]$ and among children younger than 16 years, in northwestern Ontario, with a rate of 2.5/1000 [33]. In Japan, Type II is the most common type of diabetes in children, with an incidence rate of 2.8 to $4.6 / 100,000$ children per year [34-36]. The prevalence of Type II diabetes among children of other ethnicities has been less well studied but there is evidence that it is higher among children of Mexican and African-American origin than in Caucasians $[11,37]$. These data, however, come from reviews of diabetes clinic groups and not from systematic, population based screening for diabetes. As Type II diabetes may be asymptomatic, the prevalence of this disorder is likely to be higher than generally reported in these studies.
In children, the prevalence of Type II diabetes seems to be high and rapidly increasing in populations with a relatively high prevalence of diabetes among adults $[10,37,38]$. In the Cincinnati area the proportion of children with Type II diabetes among 10 to 19 -year-old patients with diabetes increased from $4 \%$ in $1982-1991$ to $16 \%$ in 1994 [10]. During the period from 1975 to 1990 , the incidence rates of Type II diabetes in school children in Tokyo showed a 1.5-fold increase, along with a similar increase in the prevalence of obesity [36].

Type II diabetes of early onset may represent a distinct clinical and genetic syndrome due to inheritance of a diabetogenic gene or genes from both parents [39]. Type II diabetes in Pima Indians has a substantial genetic component [22]. However, a smaller effect of paternal than of maternal diabetes on diabetes prevalence in offspring has been shown, as well as a significantly higher prevalence of diabetes in offspring of women with diabetes in pregnancy than in offspring of non-diabetic or pre-diabetic women [23]. These data indicate that the intrauterine environment is an important determinant of Type II diabetes in Pima Indian children. In Pima Indians, both prevalence and incidence of diabetes have increased over time in all ages, but especially in early and middle adulthood [8]. This increase is, again, strong evidence for environmental determinants of the disease.

To determine possible reasons for the increase in prevalence of diabetes over time, we examined the effect of three environmental risk factors for diabetes development in Pima children. A significant increase in the mean weight (adjusted for age and height), and in the prevalence of intrauterine exposure to diabetes over 30 years of follow-up, but no changes in birth weight distribution were found. Compared with Pima children in 1965, in 1991 the children were much heavier for height, suggesting that the degree of obesity has increased [40]. As shown in Figure 2, it appears that the whole population is becoming heavier over time; the tendency is, however, greater for heavier than for lighter children. It has been shown [41] that in Pima Indians, obesity (assessed according to the percent relative weight) develops at a high rate in early childhood and the diabetic intrauterine environment is an important determinant of obesity during the first 20 years of life. In the multivariate analysis (Table 5), the increase in the prevalence of Type II diabetes in Pima children was almost entirely accounted for by the effect of an increase in the weight and height and in the frequency of intrauterine exposure to diabetes. Addition of paternal diabetes to the model did not change the findings.

The rates of Type II diabetes in Pima children have increased consistently during the past 30 years, along with an increasing weight, although Type II diabetes is still rare under 10 years of age. Exposure to diabetes in utero is a strong determinant of diabetes in 
Pima children. A vicious cycle associated with increasing frequencies of diabetic pregnancy [42], contributes to the increasing prevalence of Type II diabetes, as well as to the shift towards younger ages at onset of diabetes. However, life-style changes that have affected this population in the last century, such as changes in diet and dramatic reduction in physical activity, may represent the underlying causes of the epidemic of Type II diabetes seen in Pima Indian children. In the absence of better methods of treatment or prevention, these changes will probably be reflected in the earlier onset of serious vascular complications.

Acknowledgements. We thank the members of the Gila River Indian Community and the staff of the Diabetes and Arthritis Epidemiology Section for making this study possible.

\section{References}

1. Bennett PH, Burch TA, Miller M (1971) Diabetes mellitus in American (Pima) Indians. Lancet II:125-128

2. Knowler WC, Bennett PH, Hamman RF, Miller M (1978) Diabetes incidence and prevalence in Pima Indians: a 19fold greater incidence than in Rochester Minnesota. Am J Epidemiol 108: 497-504

3. Gohdes D (1995) Diabetes in North American Indians and Alaska Natives. In: Harris N (ed) Diabetes in America, 2nd edn. NIH Publication Bethesda No 95-1468; pp 683-703

4. Knowler WC, Pettitt DJ, Savage PJ, Bennett PH (1981) Diabetes incidence in Pima Indians: contributions of obesity and parental diabetes. Am J Epidemiol 113: 144-156

5. Knowler WC, Bennett PH, Bottazzo GF, Doniach D (1979) Islet cell antibodies and diabetes mellitus in Pima Indians. Diabetologia 17: 161-164

6. Savage PJ, Bennett PH, Senter GR, Miller M (1979) High prevalence of diabetes in young Pima Indians. Diabetes 28: 937-942

7. Katzeff HL, Savage PJ, Barclay-White B, Nagulesparan M, Bennett PH (1985) C-peptide measurement in the differentiation of Type I (insulin-dependent) and Type II (non-insulin-dependent) diabetes mellitus. Diabetologia 28: 264-268

8. Knowler WC, Pettitt DJ, Saad MF, Bennett PH (1990) Diabetes mellitus in Pima Indians: incidence, risk factors and pathogenesis. Diabetes Metab Rev 6: 1-27

9. Cook VV, Hurley JS (1998) Prevention of Type II diabetes in childhood. Clin Pediatr 37: 123-131

10. Pinhas-Hamiel O, Dolan LM, Daniels SR, Standiford D, Khoury PR, Zeitler P Increased incidence of non-insulindependent diabetes mellitus among adolescents. J Pediatr (Phila) 128: 608-615

11. Scott CR, Smith LM, Cradock MM, Pihoker C (1997) Characteristics of youth-onset non insulin-dependent diabetes mellitus at diagnosis. Pediatrics 100: 84-91

12. Glasser NS (1997) Non-insulin-dependent diabetes mellitus in childhood and adolescence. Pediatr Clin North Am 44: 307-337

13. Dean H (1998) NIDDM-Y in First Nation Children in Canada. Clin Pediatr (Phila) 37: 89-97

14. Pihoker C, Scott CR, Lensings SY, Cradock MM, Smith J (1998) Non-insulin-dependent diabetes mellitus in Afri-
can-American youths of Arkansas. Clin Pediatr (Phila) 37: 97-103

15. World Health Organization Group on Diabetes Mellitus (1985) Technical report series no 727, WHO, Geneva

16. Zeger SL, Liang KY (1986) Longitudinal data analysis for discrete and continuous outcomes. Biometrics 42: 121-130

17. Pettitt DJ, Bennett PH, Saad MF, Charles MA, Nelson RG, Knowler WC (1991) Abnormal glucose tolerance during pregnancy in Pima Indian women: long-term effects on the offspring. Diabetes 10 [Suppl 2]:126-130

18. McCance DR, Pettitt DJ, Hanson RL, Jacobsson LTH, Knowler WC, Bennett PH (1994) Birth weight and non-insulin dependent diabetes: thrifty genotype, thrifty phenotype, or surviving small baby genotype? BMJ 308: 942-945

19. Tattersall RB (1974) Mild familial diabetes with dominant inheritance. QJM XLIII:339-357

20. Dean H (1998) Diagnostic criteria for non-insulin-dependent diabetes in youth (NIDDM-Y). Clin Pediatr (Phila) 37: 67-73

21. Fajans SS, Bell GI, Bowden DW, Halter JB, Polonsky KS (1966) Maturity onset diabetes of the young (MODY). Diabet Med 13:S90-S95

22. Hanson RL, Elston RC, Pettitt DJ, Bennett PH, Knowler WC (1995) Segregation analysis of non-insulin-dependent diabetes mellitus in Pima Indians: Evidence for a major gene effect. Am J Hum Genet 57: 106-170

23. Pettitt DJ, Aleck KA, Baird HR et al. (1988) Congenital susceptibility to NIDDM: role of intrauterine environment. Diabetes 37: 622-628

24. Knowler WC, McCance DR, Nagi DK, Pettitt DJ (1993) Epidemiological studies of the causes of non-insulin-dependent diabetes mellitus. In: Leslie RDG (ed) Causes of Diabetes, John Wiley \&Sons Ltd, Chichester, pp187-218

25. Hanson RL, the Pima Diabetes Genes Group (1997) Genomic scan for markers linked to type II diabetes in Pima Indians. Diabetes 46 [Suppl 1]:51(Abstract)

26. Janssen RC, Bogardus C, Takeda J, Knowler W, Thompson DB (1994) Linkage analysis of acute insulin secretion with GLUT2 and glucokinase in Pima Indians and the identification of a missense mutation in GLUT2. Diabetes 43: $558-563$

27. Drash AL (1987) The classification of diabetes mellitus in children and adolescents. Acta Paediatr Jpn 29: 325-334

28. Arslanian S, Becker D Drash A (1994) Diabetes mellitus in the child and adolescent. In: Kappy MS, Blizzard RM, Migeon CJ (eds) The diagnosis and treatment of endocrine disorders in childhood and adolescence. Charles $\mathrm{C}$ Thomas, Springfield, pp 961-1026

29. Kyllo CJ, Nuttall FQ (1978) Prevalence of diabetes mellitus in school-age children in Minnesota. Diabetes 27: 57-60

30. Sperling MA (1997) Aspects of the etiology, prediction, and prevention of insulin dependent diabetes mellitus in childhood. Pediatr Clin North Am 44: 269-284

31. Dean H, Moffatt MEK (1988) Prevalence of diabetes mellitus among Indian children in Manitoba. Arctic Med Res 47: 532-534

32. Dean HJ, Mundy RL, Moffatt M (1992) Non-insulin-dependent diabetes mellitus in Indian children in Manitoba. Can Med Assoc J 147: 52-57

33. Harris SB, Perkins BA, Whalen-Brough E (1996) Non-insulin-dependent diabetes mellitus among First Nations children. New entity among First Nations people of north western Ontario. Can Fam Physician 42: 869-876

34. Otani T, Yokoyama Y, Higami Y, Kasahara T, Uchigata Y Hirata Y (1990) Age of onset and type of Japanese younger diabetics in Tokyo. Diabetes Res Clin Pract 10: 241-244 
35. Owada M, Hanaoka Y, Tanimoto Y, Kitagawa T (1990) Descriptive epidemiology of non-insulin dependent diabetes mellitus detected by urine glucose screening in school children in Japan. Acta Paediatr Jpn 32: 716-724

36. Kitagawa T, Owada M, Urakami T, Tajima M (1994) Epidemiology of Type I (insulin-dependent) and Type II (non-insulin-dependent) diabetes mellitus in Japanese children. Diabetes Res Clin Pract 24 [Suppl]:7-13

37. Glasser N, McFeely M, Jones K (1995) Non-insulin dependent diabetes mellitus in childhood. J Invest Med 43: 134A

38. Neufeld N, Raffel L, Landon C (1993) Childhood onset of type II diabetes mellitus in Hispanic Americans. Clin Res 41: $70 \mathrm{~A}$
39. O'Rahilly S, Spivey RS, Holman RR, Clark A, Turner RC (1987) Type II diabetes of early onset: a distinct clinical and genetic syndrome? BMJ 294: 923-928

40. Knowler WC, Pettitt DJ, Saad MF et al. (1991) Obesity in the Pima Indians: its magnitude and relationship with diabetes Am J Clin Nutr 53: 1543S-1551S

41. Pettitt DJ, Baird HR, Aleck KA et al. (1983) Excessive obesity in offspring of Pima Indian women with diabetes during pregnancy. N Engl J Med 308: 242-245

42. Pettitt DJ (1996) Diabetes in subsequent generations. In : Dornhorst A, Hadden DR (eds) Diabetes and pregnancy : an international approach to diagnosis and management. John Wiley \& Sons Ltd, Chichester, pp 367-376 